\title{
Improving the Torque Generation in Self-Sensing BLDC Drives by Shaping the Current Waveform
}

\author{
Virginia Manzolini \\ Department of Industrial Engineering, \\ University of Padova, Padova, Italy
}

\author{
Araz Darba and Frederik De Belie \\ Department of Electrical Energy, Systems and Automation, \\ Ghent University, Gent, Belgium
}

\begin{abstract}
Brushless DC drives are widely used in different fields of application because of their high efficiency and power density. Torque ripple can be considered one of the drawbacks of these drives. This paper proposes a method to reduce the torque ripple in BLDC drives. For this reason, the current amplitude is adapted to the rotor position rather than to be kept constant as done in a conventional commutation method. This is done by computing an optimum reference current based on the phase back-EMF waveform. The proposed approach is implemented in a self-sensing drive so its applicability to self-sensing BLDC motor drives is verified. Simulation and experimental results are given and discussed to show that the proposed method actually is able to improve torque production.
\end{abstract}

\section{INTRODUCTION}

The permanent magnet brushless DC drive, briefly called BLDC drive, is widely used in many different fields of application such as the industrial area, household appliances, automotive and aerospace. The reason of interest in this type of devices is that they have significant advantages such as high efficiency and high power density.

The brushless DC drive is controlled by means of Hall sensors. The use of sensors to measure the rotor position has some significant drawbacks: higher cost and increased hardware complexity, lower noise immunity and increased size of the drive machine, moreover the reliability decreases.

Almost all of these drawbacks can be eliminated or reduced with the use of position sensorless or self-sensing control. In self-sensing techniques the position information is estimated using measurements of other physical quantities, usually the currents and voltages of the machine windings. An overview on the self-sensing and self-sensing techniques can be found in [1] where the self-sensing methods are classified depending on the physical quantities used for the estimation. The most frequently used self-sensing method for BLDC drives is to detect the back-EMF zero-crossing moments. Examples of the use of zero-crossings detection can be found in [2], [3] and [4].

Square-wave phase currents waveforms are often generated in phase with the trapezoidal phase back-EMF waveforms. Such current waveforms are used as it is assumed it will deliver constant power and torque. However in practice a ripple is present in the torque and it could cause vibration, noise and speed ripple leading to a degradation of the motor's control performances [5]. In some sensitive industries and applications an almost constant torque is necessary and so the conventional control method is not an option to be employed [6]. Therefore a lot of research with the aim of reducing torque ripple has been done and methods to avoid both commutation ripple and ripple due to the distortion of the back-EMF have been developed.

The commutation torque ripple is caused by the difference in rising and falling times of the commutating phase current provoked by the action of freewheeling diodes. When the rising and falling rates are unbalanced a current flows in the non-commutating phase current.

Some researchers have proposed as a solution to modify the applied voltage during the commutations [7]. The drawback of this technique is that in order to implement them the topology of the control circuit has to be changed. By controlling the duty cycle of the pulse width modulation during commutations rising and falling rates can be balanced. In [8] the authors exploits this technique and uses a simple detection circuit to identify the length of commutations. Compared to the approach proposed in [9] the computation of the commutation duration is not required.

The current commutation is not the only cause of torque ripple. For practical reasons, such as non-ideality and nonuniformity of the magnetic material, design trade-offs and manufacturing limitations, it is very difficult to construct motors with exactly the desired trapezoidal back-EMF [6]. When the back electromotive force differs from the ideal trapezoidal one torque ripple appears even though the motor is fed with ideal square wave currents.

To reduce the torque ripple of BLDC motors with non-ideal or distorted back-EMF the main idea is to feed the motor with current waveforms that consider the real back-EMF shape. In [10] the techniques that address this problem are classified in two main groups: either methods that use direct torque control or modulation methods.

In [11] the use of direct torque control to reduce torque ripple of BLDC motors with distorted back-EMF is proposed. The output voltage is calculated starting from the required torque and an offline measure of the back-EMF waveform.

In [10] the phase currents are directly controlled by means of PWM. The duty cycle is calculated in real time based on the back-EMF waveform of the motor that are measured offline.

Also a model predictive control strategy minimising a cost function that takes into account the torque harmonics can help in reducing the torque ripple [12]. 
An alternative approach to regulate the current using the back-EMF information consists in calculating an optimised reference current. In [5] this method is used to optimize the current in both the commutation mode and two-phase conduction mode. For this aim the back-EMF in real time is necessary and the authors propose to use an observer based on applied voltages and phase currents in order to estimate this waveform.

In this paper the problem of the torque ripple generated in BLDC motor with distorted back electromotive force is addressed. In particular an approach that can be applied to self-sensing drives is proposed. The torque ripple reduction is achieved by optimising the current reference tacking measurements of the back-EMF rather than an observed value. Simulation and experimental results are given in order to prove the validity of the proposed technique.

\section{Computing the Reference Current}

A reduction of the torque ripple caused by a distorted back-EMF can be achieved by computing a current reference that takes into account the real shape of the motor's back electromotive force.

For this the BLDC machine model described in [13] is considered. In a BLDC motor with symmetrical three-phase windings the generated electromagnetic torque can be expressed as

$$
T_{e}=\frac{e_{a} i_{a}+e_{b} i_{b}+e_{c} i_{c}}{\omega_{m}}
$$

If the inductances of the stator windings are neglected it can be assumed that the phase currents can commutate instantly. In these conditions at each moment only two phases are conducting current. Hereafter it is supposed that the current flows from phase a to phase $b$ winding and phase $c$ is the silent one. In this condition the torque can be expressed as

$$
T_{e}=\frac{\left(e_{a}-e_{b}\right) i_{a}}{\omega_{m}}
$$

Therefore if the reference electromagnetic torque $T_{e}^{R}$, the back-EMF and the mechanical speed are known, an optimized reference current can be calculated as

$$
i_{o p t}^{R}=\frac{T_{e}^{R} \omega_{m}}{\left(e_{a}-e_{b}\right)}
$$

Assuming ideal trapezoidal back-EMF the electromagnetic torque can be approximate as

$$
T_{e}=2 k_{t} i_{a}
$$

where $k_{t}([N m / A])$ is the torque constant that represents the amount of torque generated by the machine per each Ampere of current flowing in the stator windings. So the required reference torque can be calculated as

$$
T_{e}^{R}=2 k_{t} i^{R}
$$

where $i^{R}$ is the current reference generated by the speed control. Substituting (5) in (3) the optimisation of the reference current can be done using

$$
i_{\text {opt }}^{R}=\frac{2 k_{t} i^{R} \omega_{m}}{\left(e_{a}-e_{b}\right)}
$$

The output of the speed controller, the mechanical speed as well as the line-to-line back-EMF measured between the two conductive phases, are required in order to apply the optimisation.

In the following part two procedures for estimating the lineto-line back-EMF are presented and analysed.

\section{A. Back-EMF estimation based on mechanical equation}

The profile of the back-EMF influences the one of the torque and a ripple in the torque produces a similar ripple in the speed. The influence of the torque oscillation on the speed is much more evident in low inertia drives. The main idea behind this method of estimation is that by analysing the speed variation is possible to estimate the back electromotive force that contributes to the generation of the torque. In fact the magnetic field change due to the rotor speed induces a BEMF voltage in the stator windings. The line-to-line back-EMF between the two conductive phases produces the electromagnetic torque and can be expressed as

$$
e_{a}-e_{b}=k_{e} \omega_{m}\left(F_{a}-F_{b}\right)
$$

where $k_{e}([\mathrm{~V} / \mathrm{krpm}])$ is the voltage constant and represents the quantity of BEMF voltage produced by the BLDC per each $\mathrm{krpm}$ of rotor speed. $F$ is called speed normalised back-EMF and determines the BEMF profile. For an ideal BLDC it is a trapezoidal function.

The torque generated by the motor can be expressed as

$$
T_{e}=k_{t} i_{D C}\left(F_{a}-F_{b}\right)
$$

and from this equation an expression for the difference $F_{a}-F_{b}$ can be found and substituted in (7) that becomes

$$
e_{a}-e_{b}=\frac{k_{e} \omega_{m} T_{e}}{k_{t} i_{D C}}
$$

The electromagnetic torque presented in this expression can be evaluated using the mechanical equation, but information about the load torque is necessary. The load torque estimation, based on the measured back-EMF of the silent phase, proposed in [13] is employed. The final expression used for the estimation is

$$
e_{a}-e_{b}=\frac{k_{e} \omega_{m}}{k_{t} i_{\text {meas }}}\left(J \frac{d \omega_{m}}{d t}+\hat{T}_{l}\right)
$$

\section{B. Back-EMF estimation based on electrical equation}

When no current control is applied the current waveform is determined by the back electromotive force. In fact in this condition the voltage applied at the phase windings is constant and so the voltage drop over the phase impedance varies according to the back-EMF. As a consequence from the current shape it is possible to deduce the one of the back electromotive 
force. Even if a control is applied the back-EMF influences the one of the current.

Assuming, as in the previous sections, that the current flows from phase $a$ to $b$, the line-to-line back-EMF between the conductive phases can be expressed as follow

$$
e_{a}-e_{b}=\left(V_{a}-V_{b}\right)-2 R i_{a}-2 L \frac{d i_{a}}{d t}
$$

The voltage $V_{a}-V_{b}$ is equal to the supply voltage $V_{D C}$ multiplied by the duty cycle $\delta$ of the PWM that is applied at the inverter switches to control the current. Therefore the equation for the estimation of the back electromotive force becomes

$$
e_{a}-e_{b}=\delta V_{D C}-2 R i_{D C}-2 L \frac{d i_{D C}}{d t}
$$

This estimation method presents some computation difficulties related to the calculation of the DC current derivative. The fundamental component of this term is low if compared with the back electromotive force but it has an high harmonic content. In fact the voltage drop over the inductance $\mathrm{L}$ is varied by the PWM action. As a consequence the DC current on which the estimation is based has an important ripple. In order to avoid these computation problems the derivative should take into account the sampled profile of the current.

Another problem related to the computation of the current derivative has to be considered. During commutations in fact the current varies significantly and, as a consequence, the derivative assumes large values that affect the estimation. A solution to this problem is to sample and hold the current, avoiding samples during commutation intervals. The drawback of this solution is that it requires the knowledge of the commutation time.

\section{PROPOSED CURRENT OPTIMISATION}

The back-EMF estimation methods proposed in the previous section are correct in principle but they are not suitable to be applied in self-sensing drives. In particular the technique based on the mechanical equation requires a very precise speed information. In fact the speed ripples used for the estimation are very small, above all in high inertia motors. Moreover in a self-sensing drive where only speed estimations can be used they are very difficult to detect.

The method based on the electrical equation presents, as stated before, some computation difficulty. Moreover it is not apt to be applied in drives where the measurements of the phase currents are not available. In fact in this situation it is not easy to determine the length of the commutations necessary for the current sampling. Alternatively it is possible to hold the current constant for a fixed time interval. Nevertheless the duration of the commutation is dependent on the working speed so the time interval has to be chosen carefully: a short sampling interval does not solve the problem of the derivative computation while a long one could affect the shape of the estimated back-EMF and, as a consequence, the performance of the optimisation. For these reasons to apply the optimised

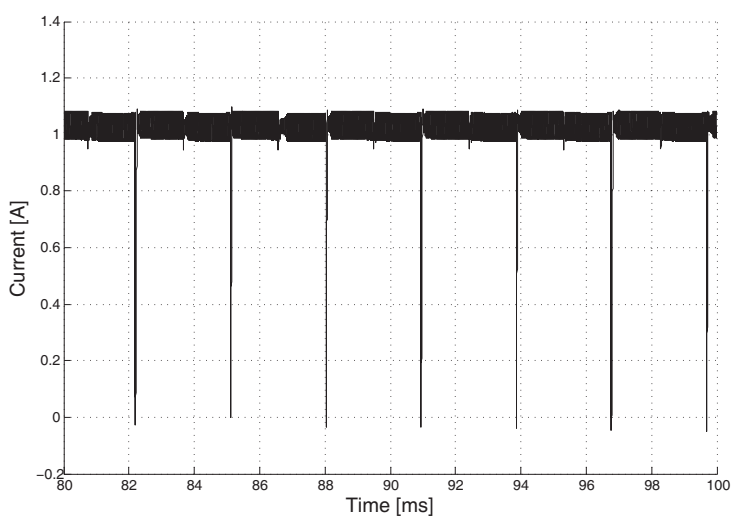

(a) conventional current control

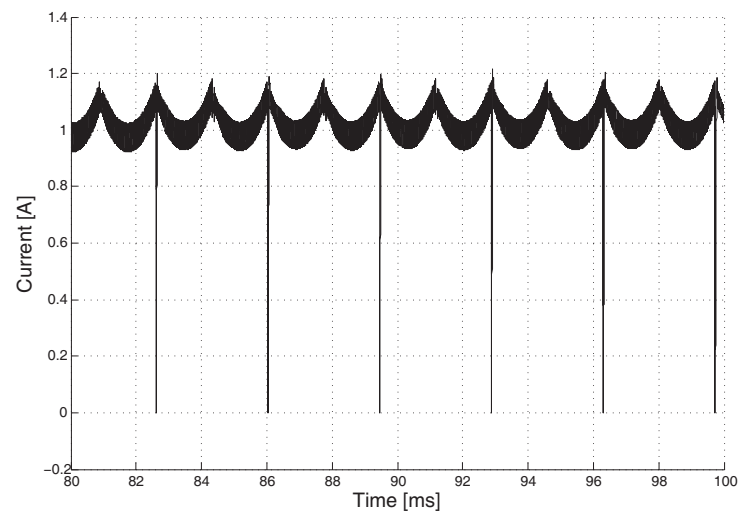

(b) improved current control

Fig. 1: Simulated DC current waveform comparison.

current control in a self-sensing BLDC motor drive the backEMF force is measured directly from the motor. This allows to solve most of the computational problems, like computing the derivatives of speed or current, that characterise the analysed back-EMF estimations. However while the BLDC is working it is possible to measure online only the back-EMF of the unexcited phase, that is not useful in order to implement the current waveform optimisation. Therefore offline measurements of the line-to-line have to be used. The offline measures are stored in a look-up table and used to compute the optimised current reference as shown in (6).

A widely used self-sensing technique for BLDC motor drives is the detection of the back-electromotive force zerocrossing moments to estimate the commutation instants. Usually, when this kind of methods are employed the assumption that the speed does not change between two consecutive commutations is done. During speed transients this assumption leads to a degradation of the performance of the drive. The technique proposed in [2] and [3] is employed together with the current reference optimisation.

\section{A. Simulation results}

The simulations presented in this section are carried out using Matlab/Simulink and a model of a BLDC that includes 


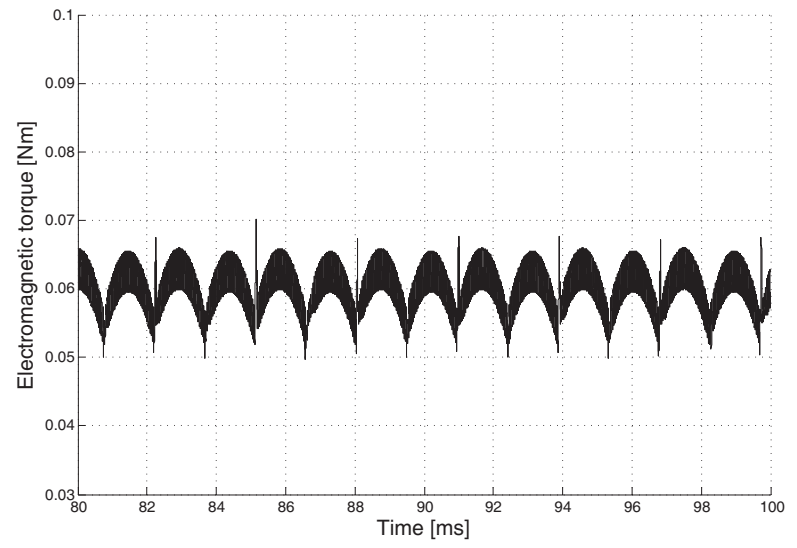

(a) conventional current control

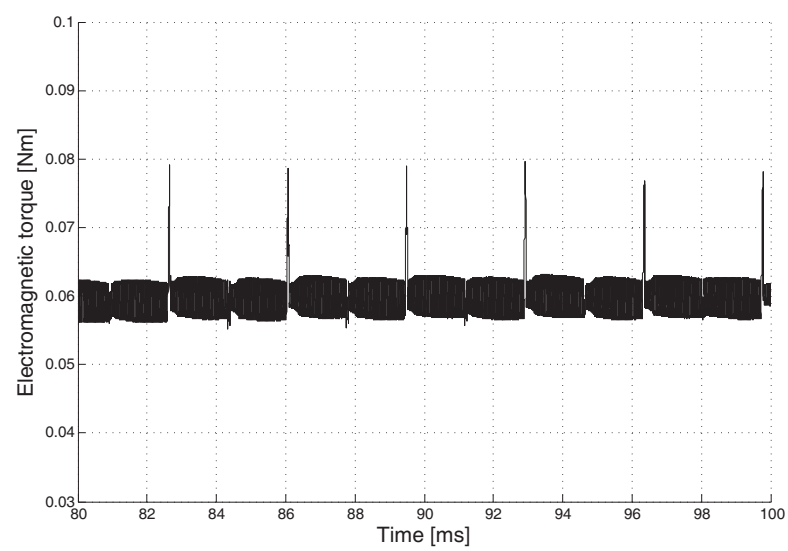

(b) improved current control

Fig. 2: Simulated electromagnetic torque comparison.

the real back electromotive force waveform.

In Fig. 1(a) and 1(b) the DC current that results from the use of the conventional reference and of the optimised one are plotted. It can be noticed that the optimisation actually affects the waveform of the current.

Fig. 2(a) represents the torque generated by the BLDC model when square wave currents feed the motor and a ripple is visible. Comparing the torque with the optimised current it can be noticed that the shape of the two waveforms are complementary. This is a result of the fact that both the torque and the optimised current are influenced by the back-EMF. In Fig. 2(b) the torque generated by the motor fed by the optimised current is plotted and a reduction of the torque ripple is evident.

\section{EXPERIMENTAL RESULTS}

In this section some experimental results are given and analysed in order to verify and prove the real contribution of the proposed current optimisation in reducing torque ripple and its applicability to self-sensing BLDC motor drives. The practical setup employed for this work is represented in Fig. 3. The optimised current control is implemented on SPARTAN

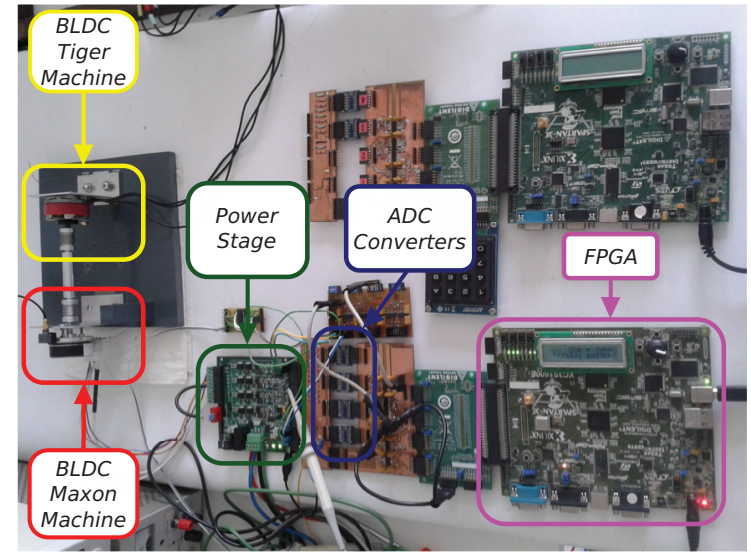

Fig. 3: Employed practical setup.

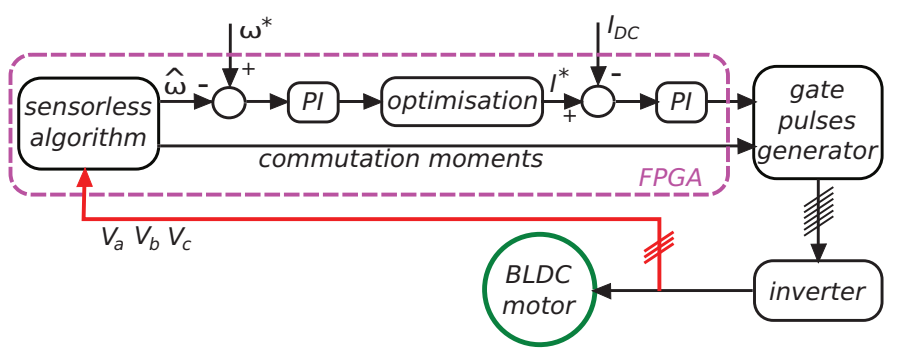

Fig. 4: Scheme of the BLDC motor drive.

3E field-programmable gate array (FPGA) evaluation board. This FPGA board has a maximum clock frequency of 50 MHz. The control and power circuits are isolated using IL715 digital isolators to guarantee galvanic isolation. The isolator is characterised by a low propagation delay of $10 \mathrm{~ns}$. The quantities measured from the motor are converted to digital data using some ADC converters that have a resolution of 12 bits and a maximum sampling frequency of 1 MSPS. All measured data pass through the galvanic isolator before reaching the FPGA. Inside the FPGA they are elaborated and used for the control algorithm that generates the control pulses for the inverter switches. These control signals are applied to the inverter after passing through the digital isolator. Two lowpower BLDC machines are employed in the setup: a BLDC Maxon machine, whose parameters are reported in Table I, is used as motor and controlled by mean of the FPGA and another BLDC machine is used as mechanical load. A scheme of the drive is represented in Fig. 4.

A description of the available measures on the described setup and of the way in which they are done is now provided. First of all the DC current is measured using a shunt resistor $R_{i}$ : the voltage drop over it, $V_{i}$, is measured and gives an indication of the current. The shunt resistor is located in the negative rail of the inverter and the voltage is measured with respect to the ground. The three terminal voltages of the motor and a virtual neutral point voltage are also measured with respect to the low side of the supply. In Fig 5 the measured DC current is plotted. It can be seen that, except 


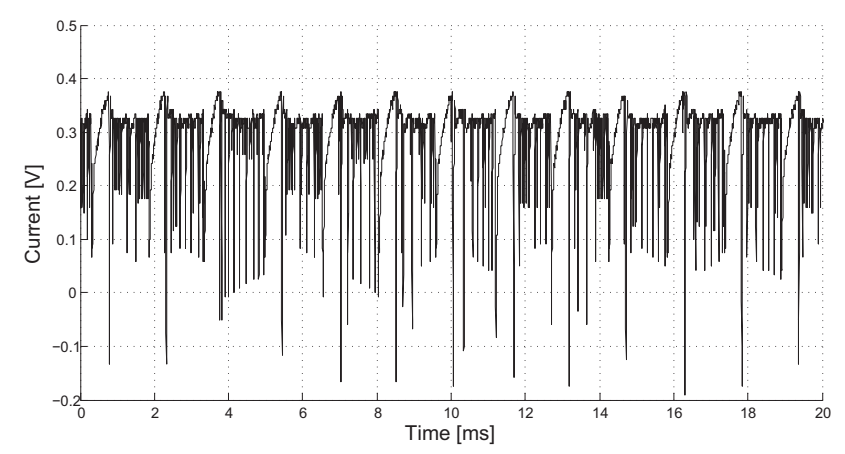

(a) conventional current control

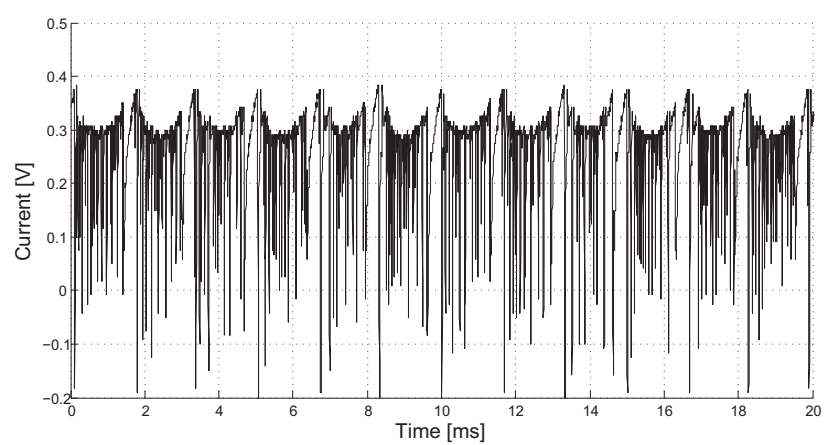

(b) improved current control

Fig. 5: Comparison of DC current measured through $R_{i}$.

for the commutation moments, the current is almost constant when the normal current control is used (Fig 5(a)). On the contrary when the improved current control is used (Fig 5(b)) the current varies between two commutations according to the back electromotive force shape represented in Fig. 6.

\section{A. Torque ripple indirect measurement}

The purpose of the implemented improved control is to reduce the torque ripple caused by the deviating trapezoidal back-EMF waveform. This is done by adapting the current to the back electromotive force profile. conforms the back-EMF. To verify that this kind of current control brings improvements in the torque an accelerometer was used to measure the vibrations induced by the torque ripple. In fact torque ripple

TABLE I: Parameters of the Maxon machine.

\begin{tabular}{|c|c|}
\hline Number of pole pairs & 8 \\
\hline Stator resistance & $1.03 \Omega$ \\
\hline Stator inductance & $0.572 \mathrm{mH}$ \\
\hline Rotor inertia & $1.35 \times 10^{-5} \mathrm{kgm}^{2}$ \\
\hline Nominal current & $2.33 \mathrm{~A}$ \\
\hline Nominal voltage & $24 \mathrm{~V}$ \\
\hline Nominal torque & $83.4 \mathrm{mNm}$ \\
\hline Torque constant & $33.5 \mathrm{mNm} / \mathrm{A}$ \\
\hline Speed constant & $3.51 \mathrm{~V} / \mathrm{krpm}$ \\
\hline
\end{tabular}

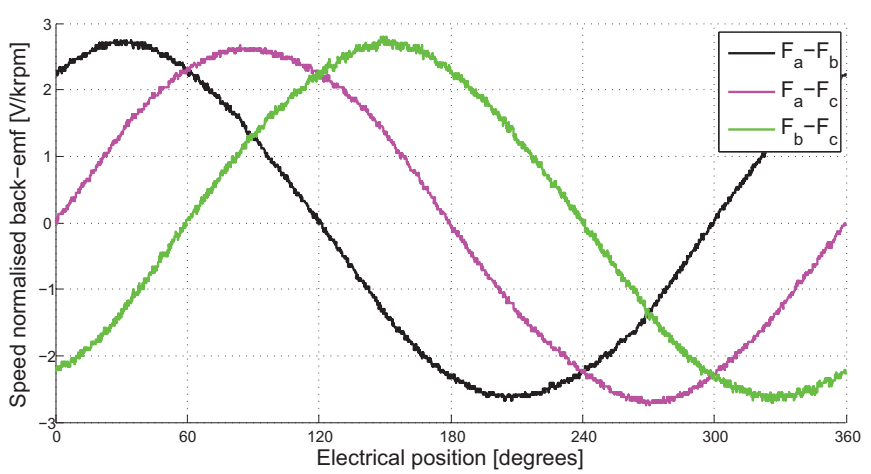

Fig. 6: Measured line-to-line back electromotive force.

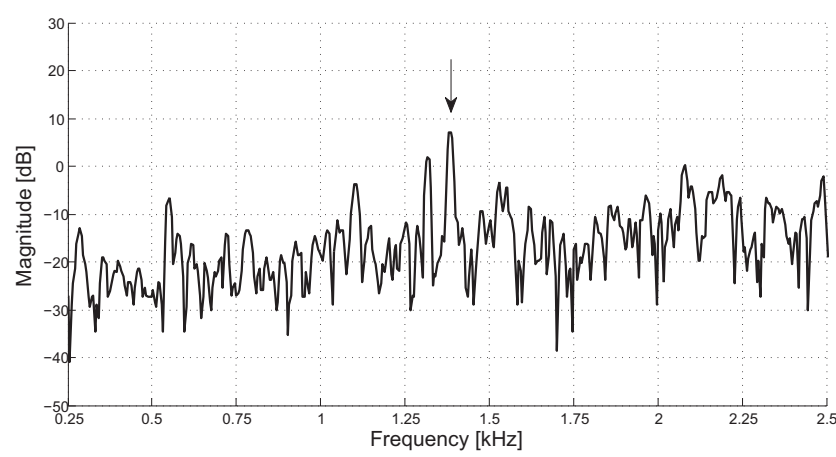

(a) without optimised reference

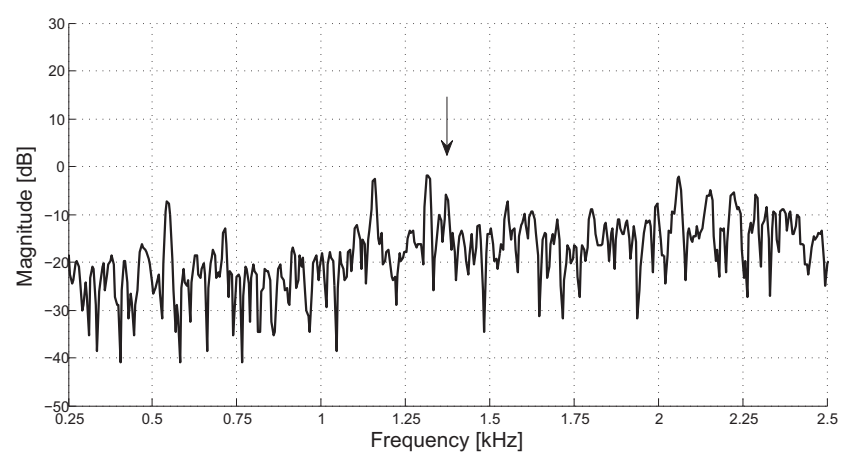

(b) with the optimised reference

Fig. 7: FFT of the accelerometer output obtained at $1736 \mathrm{rpm}$.

causes vibrations that as a consequence are an indirect measure of the ripple. So an accelerometer was mounted on the stator to measure the stator vibration. It is important to notice that the output of the sensor is a voltage. The measurements depend on how the mechanical system responds to the ripple in the torque and this response is, in general, frequency dependent. Therefore it is not possible to obtain an accurate $\mathrm{V} / \mathrm{Nm}$ conversion without a precise knowledge of the mechanical response to torque ripple at each frequency [14].

The causes of stator vibration are numerous and the torque ripple is only one of these. So it is important to determine which vibration are torque ripple-induced in order to evaluate 


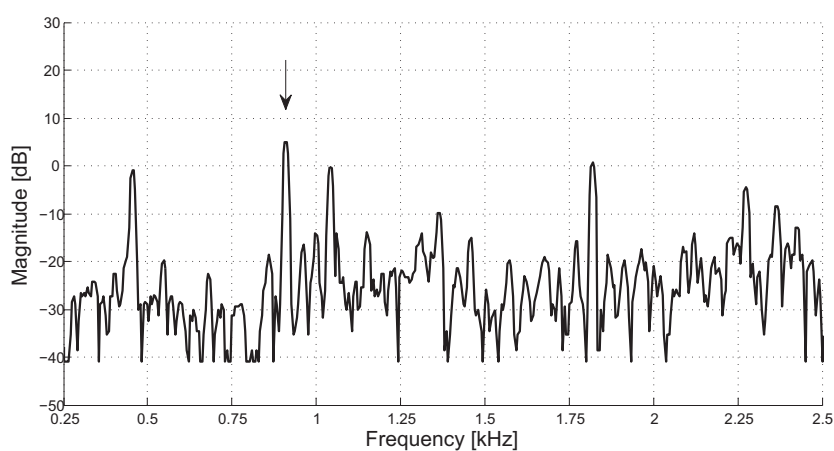

(a) without optimised reference

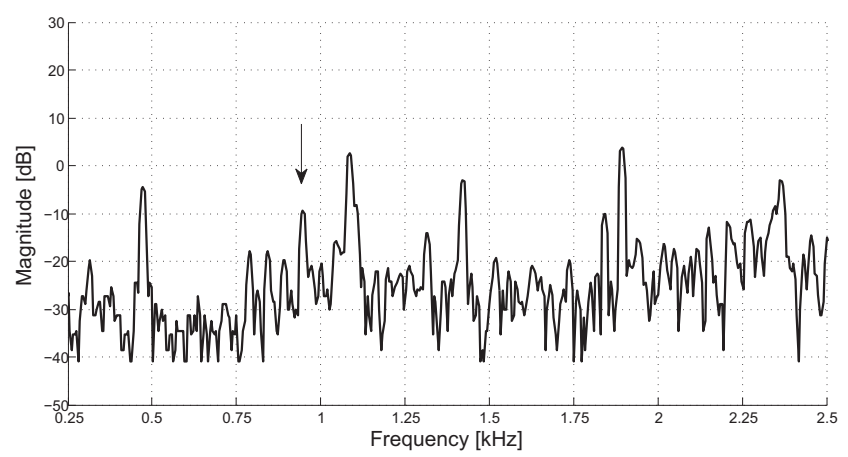

(b) with the optimised reference

Fig. 8: FFT of the accelerometer output obtained at $938 \mathrm{rpm}$.

correctly the effect of the improved current control. The ripple in the torque is periodic with a period of 60 electrical degrees as a consequence also the vibration that it induces should be periodic with the same period. So the frequency of the rippleinduced vibration can be calculated in order to distinguish it from the vibrations caused by other reasons. The frequency is speed dependent and can be computed starting from the working speed of the motor as

$$
f_{T}=\frac{\omega_{r p m p}}{10}
$$

where $p$ is the number of pole pairs. Also the load machine has a distorted back-electromotive force and as a consequence generates some vibrations. However it does not influence the measure because this motor has a different number of pole pairs so it induces vibration at a different frequency.

Some tests at different speed were done and the Fourier Transform of the accelerometer output was evaluated. At every speed a spike is present in the FFT at the frequency $f_{T}$.

Moreover when the improved current control is employed a reduction of the spike's amplitude can be recognised both at load and no load condition, as can be noticed in Fig. 7 and 8 .

The general improvement that is present in the vibrations at the frequency $f_{T}$ can be interpreted as an improvement in the generated electromagnetic torque.

\section{CONCLUSION}

In this paper a modified current control is proposed in order to reduce the torque ripple of BLDC motor with distorted back electromotive force. The current waveform is determined by optimising the current reference using back-EMF offline measurements. The advantage of this method is that it can be employed also in self-sensing drives. In fact the proposed approach is implemented on an FPGA platform together with a self-sensing control based on the back-EMF zero-crossings moments so its applicability to self-sensing BLDC motor drives is verified. The experimental results show that the proposed method actually allows to reduce the stator vibration and the torque ripple significantly.

\section{REFERENCES}

[1] P. P. Acarnley and J. F. Watson, "Review of position-sensorless operation of brushless permanent-magnet machines," IEEE Transactions on Industrial Electronics, vol. 53, no. 2, pp. 352-362, April 2006.

[2] A. Darba, F. D. Belie, and J. Melkebeek, "Sensorless commutation and speed control of brushless dc-machine drives based on the back-emf symmetric threshold-tracking," in Electric Machines Drives Conference (IEMDC), 2013 IEEE International, May 2013, pp. 492-497.

[3] A. Darba, F. D. Belie, A. Salem, and J. Melkebeek, "Fpga-based implementation of the back-emf symmetric-threshold-tracking sensorless commutation method for brushless dc-machines," in 2013 IEEE International Symposium on Sensorless Control for Electrical Drives and Predictive Control of Electrical Drives and Power Electronics (SLED/PRECEDE), Oct 2013, pp. 1-6.

[4] P. Damodharan and K. Vasudevan, "Sensorless brushless dc motor drive based on the zero-crossing detection of back electromotive force (emf) from the line voltage difference," IEEE Transactions on Energy Conversion, vol. 25, no. 3, pp. 661-668, Sept 2010.

[5] C. Xia, Y. Xiao, W. Chen, and T. Shi, "Torque ripple reduction in brushless dc drives based on reference current optimization using integral variable structure control," IEEE Transactions on Industrial Electronics, vol. 61, no. 2, pp. 738-752, Feb 2014.

[6] S. M. Shakouhi, M. Mohamadian, and E. Afjei, "Torque ripple minimisation control method for a fourphase brushless dc motor with non-ideal back-electromotive force," IET Electric Power Applications, vol. 7, no. 5, pp. 360-368, May 2013.

[7] K.-Y. Nam, W.-T. Lee, C.-M. Lee, and J.-P. Hong, "Reducing torque ripple of brushless dc motor by varying input voltage," IEEE Transactions on Magnetics, vol. 42, no. 4, pp. 1307-1310, April 2006.

[8] Y. K. Lin and Y. S. Lai, "Pulsewidth modulation technique for bldcm drives to reduce commutation torque ripple without calculation of commutation time," IEEE Transactions on Industry Applications, vol. 47, no. 4, pp. 1786-1793, July 2011.

[9] Y. Liu, Z. Q. Zhu, and D. Howe, "Commutation-torque-ripple minimization in direct-torque-controlled pm brushless dc drives," IEEE Transactions on Industry Applications, vol. 43, no. 4, pp. 1012-1021, July 2007.

[10] J. Fang, H. Li, and B. Han, "Torque ripple reduction in bldc torque motor with nonideal back emf," IEEE Transactions on Power Electronics, vol. 27, no. 11, pp. 4630-4637, Nov 2012.

[11] S.-J. Kang and S.-K. Sul, "Direct torque control of brushless de motor with nonideal trapezoidal back emf," IEEE Transactions on Power Electronics, vol. 10, no. 6, pp. 796-802, Nov 1995.

[12] A. Mora, A. Orellana, J. Juliet, and R. Cardenas, "Model predictive torque control for torque ripple compensation in variable speed pmsms." has been accepted for publication in a future issue IEEE Transactions on Industrial Electronics, 2016.

[13] A. Darba, P. D'haese, F. D. Belie, and J. A. Melkebeek, "Improving the dynamic stiffness in a self-sensing bldc machine drive using estimated load torque feedforward," IEEE Transactions on Industry Applications, vol. 51, no. 4, pp. 3101-3114, July 2015.

[14] P. Beccue, J. Neely, S. Pekarek, and D. Stutts, "Measurement and control of torque ripple-induced frame torsional vibration in a surface mount permanent magnet machine," IEEE Transactions on Power Electronics, vol. 20, no. 1, pp. 182-191, Jan 2005. 